2. Rao C, Liu B, Huang D, Chen R, Huang K, Li F, et al. Nucleophosmin contributes to vascular inflammation and endothelial dysfunction in atherosclerosis progression. J Thorac Cardiovasc Surg. 2021; 161:e377-93.

3. Wang X, Ma H, Wang X. Nucleophosmin/B23 contributes to hepatic insulin resistance through the modulation of NF- $\kappa \mathrm{B}$ pathway. Biochem Biophys Res Commun. 2019;511:214-20.
4. Poston RN. Atherosclerosis: integration of its pathogenesis as a self-perpetuating propagating inflammation: a review. Cardiovasc Endocrinol Metab. 2019;8:51-61.

5. Privratsky JR, Newman DK, Newman PJ. PECAM-1: conflicts of interest in inflammation. Life Sci. 2010;17:69-82.

6. Box JK, Paquet N, Adams MN, Boucher D, Bolderson E, O'Byrne KJ, et al. Nucleophosmin: from structure and function to disease development. BMC Mol Biol. 2016;24:1-12.
See Article page e377.

\section{Commentary: Unraveling the mysteries of atherogenesis: An elusive goal}

\author{
Darrell $\mathrm{Wu}, \mathrm{MD},{ }^{\mathrm{a}}$ and Shuab Omer, $\mathrm{MD}^{\mathrm{b}}$
}

Endothelial activation, which involves alterations in chemokine receptor activity, endothelial permeability, and paracrine factor secretion, is a central hallmark of vascular inflammation, ${ }^{1}$ which in turn is a critical step in the pathogenesis of atherogenesis. Increasing evidence shows that endothelial activation is nuclear factor $\kappa$ light chain enhancer of activated B cells (NF-kB)-dependent. NF-kB activation can lead to an inflammatory phenotypic change through transcription of genes associated with chemokines, adhesion molecules, and cytokines. ${ }^{2}$

Nucleophosmin (NPM) is a multifunctional nuclear phosphoprotein that has been implicated in multiple pathways, such as transcriptional gene regulation, ribosome biogenesis, DNA repair processes, apoptosis, and cell differentiation. ${ }^{2}$ Although the function of NPM in the oxidative stress response is known, the function of NPM in arterial vascular pathogenesis is not as well characterized. ${ }^{3}$ In this issue of the Journal, Rao and colleagues ${ }^{4}$ have

From the a Division of Cardiothoracic Surgery, Baylor College of Medicine, Houston and ${ }^{b}$ Department of Advanced Cardiopulmonary Therapies and Transplantation, The University of Texas Health Science Center at Houston, McGovern Medical School, Houston, Tex.

Disclosures: Authors have nothing to disclose with regard to commercial support.

Received for publication Oct 26, 2019; revisions received Oct 28, 2019; accepted for publication Oct 30, 2019; available ahead of print Nov 28, 2019.

Address for reprints: Shuab Omer, MD, Department of Advanced Cardiopulmonary Therapies and Transplantation, The University of Texas Health Science Center at Houston, McGovern Medical School, Houston, TX 77030 (E-mail: shuab.omer@ uth.thc.edu).

J Thorac Cardiovasc Surg 2021;161:e396-7

$0022-5223 / \$ 36.00$

Copyright (c) 2019 by The American Association for Thoracic Surgery

https://doi.org/10.1016/j.jtcvs.2019.10.199
Check for updates

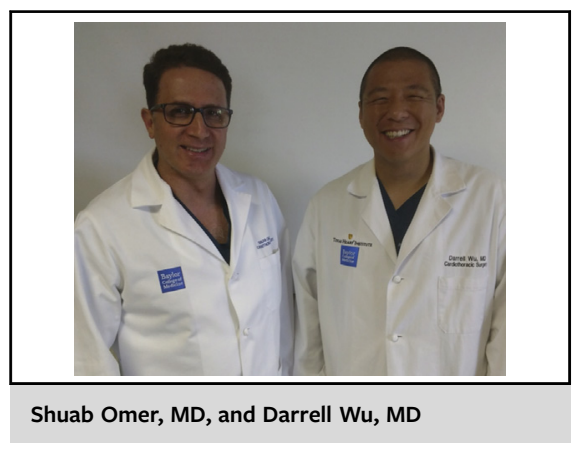

CENTRAL MESSAGE

Nucloephosmin promotes

vascular inflammation and endo-

thelial dysfunction in an NF-kB

dependent pathway.

attempted to elucidate the role of NPM in vascular inflammation and the progression of atherogenesis.

The authors first used human atherosclerotic plaques to demonstrate that, compared with aortic tissue from patients needing aortic valve replacement, NPM levels were increased and colocalized to endothelial cells. Second, they found that injection of adenovirus containing NPM shRNA into $\mathrm{ApoE}^{-/-}$mice fed a high-fat diet and knockdown of NPM attenuated atherosclerotic lesion formation, reduced vascular inflammation, and decreased NK-kB p65 phosphorylation. Third, using an in vitro model consisting of human umbilical vein endothelial cells, they found that stimulation with palmitic acid increased NPM levels and induced the expression of inflammatory cytokines, whereas NPM knockdown with siRNA attenuated this effect. Furthermore, they found that NPM physically interacted with the NF-kB p65 subunit, promoted its nuclear transposition, and increased the transcriptional activity of NF-kB promoter and enhanced binding to proinflammatory target genes, such as ICAM-1, E-selectin, IL-Ib, and IL-6. 
Although this study provides evidence of the role of NPM in vascular inflammation and atherosclerosis, there are a number of important points that bear mentioning when considering this study. First, the use of aorta as a control of carotid plaques is not necessarily the ideal comparison, as the pathogenesis of central vascular disease differs from that of peripheral vascular disease. Second, in using the $\mathrm{ApoE}^{-/-}$, model the authors did not investigate the role of NPM in dyslipidemia. Use of $\mathrm{NPM}^{-/-}$mice or double deletion might have revealed whether NPM was involved in vascular inflammation through pathways affecting dyslipidemia. Third, using CD68 as a single identifier of macrophages ignores the multiple roles of macrophages (polarization) and monocytes during inflammation. Fourth, although undoubtedly there is evidence of the involvement of NPM in vascular inflammation, the authors provide no evidence of the role of NPM in plaque stability, which is critical in cardiovascular events. Finally, whether NPM can regulate the other key regulator of vascular inflammation, namely vascular smooth muscle cells, was not investigated.

Nonetheless, the authors should be commended on their investigation into the role of NPM in vascular inflammation and atherosclerosis, which has the potential to lead to the development of a new therapeutic target in the battle against cardiovascular disease.

\section{References}

1. Galkina E, Ley K. Vascular adhesions molecules in atherosclerosis. Arterioscler Thromb Vasc Biol. 2007;27:2292-301.

2. Tak PP, Firestein GS. NF-kappaB: a key role in inflammatory disease. J Clin Invest. 2001;107-11.

3. Csiszar A, Wang M, Lakatta E, Ungvari Z. Inflammation and endothelial dysfunction during aging: role of NK-kB. J Appl Physiol. 2008;105:1333-41.

4. Rao C, Liu B, Huang D, Chen R, Huang K, Li F, et al. Nucleophosmin contributes to vascular inflammation and endothelial dysfunction in atherosclerosis progression. J Thorac Cardiovasc Surg. 2021;161:e377-93. 